\title{
Wear Striation Direction on Primate Teeth: A Scanning Electron Microscope Examination
}

\author{
ALAN S. RYAN \\ Museum of Anthropology, The University of Michigan, Ann Arbor, Michigan 48109
}

\begin{abstract}
KEY WORDS Dental microwear . Wear striation - Masticatory
\end{abstract} movement. Direction. Primates

\begin{abstract}
Two experimental methods were used to produce wear striations in one direction on unworn teeth. These include: (1) sliding 22 American Indian (Juntunen site, Michigan; Late Woodland) newly erupted incisors, by hand, across a flat glass surface covered with fine loose sand; and (2) using a unidirectional motor driven mechanical wear machine to draw 56 modern human dental extractions across a flat glass surface covered with silicon carbide powder of different grit sizes. A scanning electron microscope examination of individual wear striation morphology indicates that these wear striations begin with broad pits and have extending grooves that become narrower; characteristics that indicate the motion of wear. Patterns of wear striations on the worn dentitions of American Indians (Juntunen site) and the paleocene primate Phenacolemur pagei show similar characteristics and correspond to the buccal phase of mastication when the mandible is drawn upward, forward and slightly medially into centric occlusion. The data provided by this study can be used to test competing hypotheses concerning the direction of mandibular movement during mastication and food preparation.
\end{abstract}

\section{SHERWOOD WASHBURN AWARD-1978 \\ For an outstanding student paper}

The study of dental microwear in living and extinct mammals has provided valuable information concerning certain aspects of dental function, occlusal relations and dietary preference (Butler, '52; Mills, '55, '63, '67; Butler and Mills, '59; Gingerich, '72, '73, '76; Hiiemae and Kay, '73; Kay and Hiiemae, '74a; Kay, '73, '75, '77; Puech, '77; Shkurkin et al., '75; Walker, '76). It has been shown that functional occlusion produces two distinct microwear patterns. The first, abrasion, is characterized by polished and pitted surfaces as a result of tooth-food-tooth contact during chewing; the second, attrition, is the result of the occlusal surfaces of upper and lower teeth coming into close or actual contact during mastication, an action which produces wear facets with parallel striations (Dahlberg and Kinzey, '62; Kay and Hiiemae, '74a). The study of abrasion can yield evidence concern- ing special activities performed by the dentition as well as dietary habits (Molnar, '71, '72). Most investigations of attrition, on the other hand, have attempted the reconstruction of chewing behavior in living and extinct mammals by the analysis of the orientation of wear striations on cheek teeth (Butler, '52; Mills, '55, '63, '67; Butler and Mills, '59; Gingerich, '72, '73, '76; Kay and Hiiemae, '74a,b; Kay, '73, '75, '77; and others). Butler ('52) and Mills ('55) were the first to systematically map the orientation of striated molar wear facets and connect these facets with specific jaw movements during mastication. Mills ('55) suggested that two distinct sets of striations exist, each indicative of a specific direction or phase of mandibular movement. These two sets correspond to an initial buccal phase followed by the lingual phase of mastication. The buccal phase in- 
volves an upward, forward and medial mandibular movement until the lower jaw reaches centric occlusion whereas the lingual phase begins as the mandible moves downward, forward and medially out of centric occlusion on the active side. The buccal and lingual phases described here are identical to "Phase I" and "Phase II" of the power stroke of Hiiemae and Kay ('73) and Kay and Hiiemae ('74a). These and other studies, coupled with cineradiographic investigations of chewing behavior in living animals, have described in detail the relationship between the direction of masticatory movement and buccal and lingual phase striated molar wear facets (Crompton and Hiiemae, '70; Hiiemae and Kay, '73: Kay and Hiiemae, ' $74 \mathrm{a}, \mathrm{b}$ ).

In discussing tooth wear and dental function in primates, Gingerich ('72, '73, '76) has suggested that a distinct initial stage of mastication exists, involving "orthal retraction" of the mandible. Here, the mandible is drawn upward and backward producing striated wear facets that correspond to an initial puncturing (or sometimes crushing, depending on tooth morphology) phase and stage of mastication. This initial "orthal retraction" stage is then followed by buccal and lingual jaw movements. Contrary to Gingerich, Kay and Hiiemae ('74a) have suggested that "orthal retraction" striated wear facets are the result of accidental balancing side contact during chewing as the mandible is drawn downward and forward at the termination of the lingual phase. The interpretation of the direction of these "orthal retraction" wear striations, then, has resulted in two contradictory hypotheses.

Other competing hypotheses also have been advanced concerning the direction of mandibular movement. For example, according to Every ('60, '65, '70), attrition and certain striated wear facets are the result of thegosis (or "tooth-sharpening"), movements of the jaw that are opposite to those of mastication. These striations are produced by enamel chips scratching the tooth surface during a thegotic movement. Thus, one set of striations has been suggested to be the result of two exactly equal but opposite movements of the jaw.

At present there are no data available to provide an adequate test of these competing hypotheses. A study which can provide such data must include: (1) an experimental design focused on wear striation direction; and (2) a detailed description of the characteristics of wear striations that indicate the direction of wear. The present study is an attempt to document, and describe microscopically, those characteristics of individual wear striations that are indicative of the direction of wear. It is suggested here that the data provided by such an investigation can further our understanding of dental function and occlusal relations in both living and extinct mammals by providing the basis for falsification of present competing hypotheses.

The method of this study is to produce wear striations under controlled conditions on unworn teeth in a single direction, note those characteristics of the resulting striations that indicate the direction of wear and finally, compare these striations to those that have been produced in living and extinct animals during mastication. The ability to examine individual wear striation morphology can be achieved by using the scanning electron microscope (SEM) which provides a combination of clarity, increased depth of field, high magnification and analytical capability to study details too small to be seen either by the unaided eye or an optical microscope (Hearle, '72; Hayat, '75; Ohnsorge and Holm, '73).

\section{MA'TERIALS AND METHODS}

Two different approaches were employed to produce experimentally wear striations in one direction on unworn teeth. Each is described below.

The sample studied in the first approach (Method I; Ryan, '78) consisted of two subsamples: 25 American Indian (Juntunen site, Michigan; Late Woodland) newly erupted incisors which served as an experimental control and 21 Phenacolemur pagei (a late Paleocene primate) and 22 American Indian (Juntunen site) worn dentitions which had wear striations which were probably produced during mastication. These dental samples were provided by the Museum of Anthropology and the Museum of Paleontology, University of Michigan. The control group was examined under a binocular microscope and those teeth that were not worn and did not exhibit preservation damage were selected as a test sample $(n=22)$. The occlusal surface of each of the incisors was then drawn, by hand, in one direction (with the buccal surface as the leading edge), across a flat glass surface covered with fine loose sand. Constant, even pressure was applied to the tooth as it was drawn across this gritty surface. This method to produce 


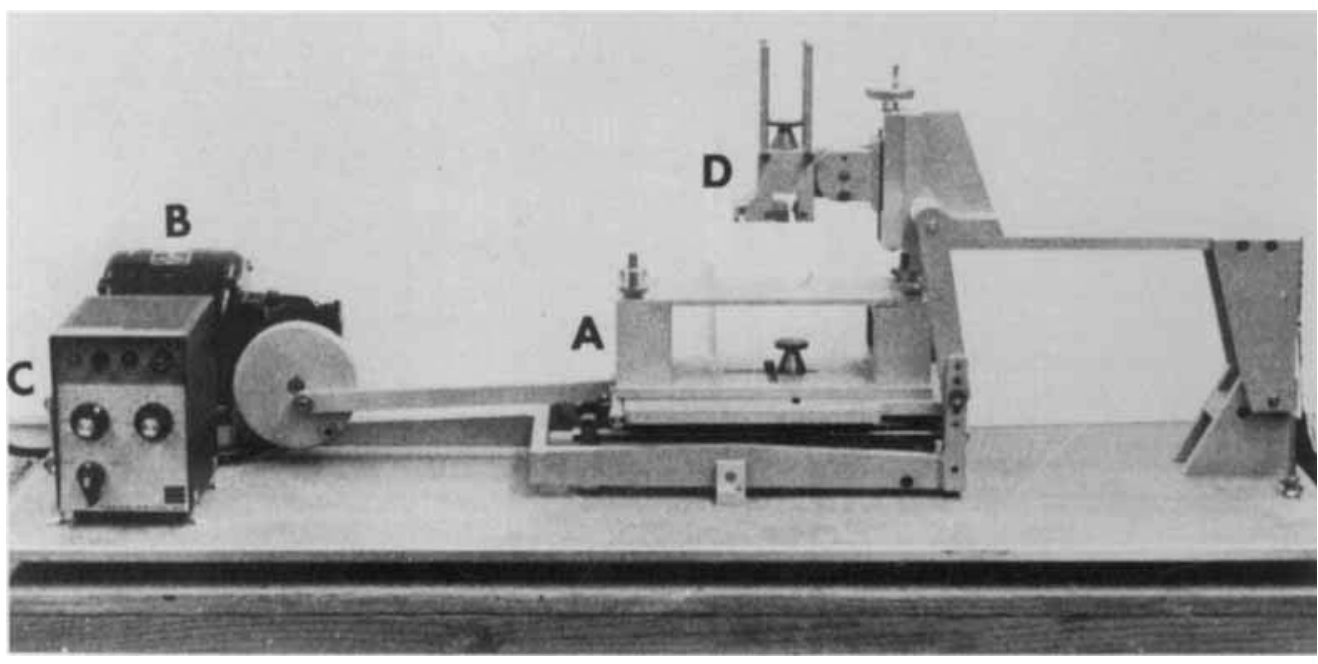

Fig. 1 Lateral view of the unidirectional motor driven mechanical wear machine used to produce experimentally wear striations on unworn teeth. A, linear mechanical slide assembly; B, Bodine gear motor (Type NSH 54RL); C, motor control unit (Type ASH 502/DC). D, adjustable load arm.

wear striations was repeated several times for each specimen.

The simplicity of this experimental design allows other investigators to independently replicate this experiment. However, using this approach certain unknown variables, such as particle size and consistency and the force on the leading edge, cannot be controlled. Control of these variables may shed light on the influence of particle size and consistency on microwear patterns and wear striation morphology. Further, the composition of grit introduced into the diet as well as occlusal forces during mastication may be inferred (see below). Therefore, a second approach (Method II) to produce experimentally wear striations in one direction was devised in an attempt to control the maximum number of variables.

A unidirectional motor driven mechanical wear machine (fig. 1) consisting of a linear mechanical slide assembly, a Bodine gear motor (Type NSH 54RL), a motor control unit (Type ASH 502/DC) and an adjustable load arm (used to hold the specimen) was specifically designed to produce vertical axis motions. Both speed and vertical force can be controlled by adjusting the RPM control on the motor control unit and by adding weights to the load arm. The slide assembly and load arm are powered by a drive wheel attached to the motor by a gear plate and to the slide assembly by a metal rod. The load arm is automatically lowered onto the slide assembly which moves at constant speed back and forth in a straight line. The load arm is then automatically lifted after each linear stroke in order to avoid bi-directional linear wear. In addition, to avoid abrupt and heavy initial vertical forces, the load arm is smoothly lowered on to the surface but at the end of the linear stroke it is rapidly lifted to prevent lagging.

A flat glass surface was mounted to the slide assembly and covered with silicon carbide powder (angular variety). Three different grit sizes were used (table 1). Care was taken to spread as evenly as possible the silicon carbide powder on the glass surface.

Fifty-six assorted modern human dental extractions provided by the University of Michigan Dental School were examined under a binocular microscope to determine areas of unworn enamel. In most cases, the midpoint of the lingual or buccal crown surfaces were free of any scratches or pits. Each tooth was secured to the load arm and gradually lowered on to the gritty glass surface until contact was made. The wear machine was then allowed to run for different lengths of time (table 1) at constant speed ( $50 \mathrm{rpm}$ ) for each test sample.

It should be emphasized that the aforementioned experiments were not designed to simulate jaw movement but rather to recreate the conditions involved in the production of wear striations of known direction on enamel when abrasive material is sandwiched between two hard surfaces as they slide across each other. 
TABLE 1

Test samples, materials and procedures used in Method II and descriptive statistics for pit size at the point of initial contact of individual wear striations

\begin{tabular}{|c|c|c|c|c|c|c|c|}
\hline \multirow{2}{*}{ Group } & \multirow[b]{2}{*}{$\mathrm{N}$} & \multirow{2}{*}{$\begin{array}{c}\text { Time (seconds) } \\
\text { at } 50 \mathrm{rpm}\end{array}$} & \multicolumn{2}{|c|}{$\begin{array}{l}\text { Silicon carbide } \\
\text { grit size }(\mathrm{mm})\end{array}$} & \multirow{2}{*}{$\begin{array}{c}\text { Vertical } \\
\text { force } \\
(\mathrm{kg})\end{array}$} & \multicolumn{2}{|c|}{$\begin{array}{l}\text { Pit size } \\
\text { (mm) }\end{array}$} \\
\hline & & & Mean & Range & & Mean & S.D. \\
\hline A & 5 & 15 & 0.1 & $0.163-0.05$ & 2 & 0.0037 & 0.0035 \\
\hline $\mathrm{B}$ & 7 & 15 & 0.03 & $0.06-0.014$ & 2 & 0.0025 & 0.0005 \\
\hline $\mathrm{C}$ & 7 & 15 & 0.016 & $0.035-0.009$ & 2 & 0.0024 & 0.0007 \\
\hline D & 7 & 15 & 0.1 & $0.163-0.05$ & 2.3 & 0.0050 & 0.0049 \\
\hline $\mathrm{E}$ & 4 & 15 & 0.03 & $0.06-0.014$ & 2.3 & 0.0038 & 0.0015 \\
\hline $\mathrm{F}$ & 8 & 15 & 0.016 & $0.035-0.009$ & 2.3 & 0.0028 & 0.0024 \\
\hline$G^{1}$ & 5 & 300 & 0.1 & $0.163-0.05$ & 2.3 & 0.0043 & 0.0006 \\
\hline
\end{tabular}

1 This test sample was not used to compute $r_{3}$ (see text).

After the experiments were performed, all teeth were then carefully cleaned with acetone in order to eliminate contamination by dust particles. A clay fence was constructed around the entire tooth, teeth or jaw, leaving the occlusal surfaces or experimentally scratched areas visible. This clay fence is made from an oil base molding clay that can be easily applied and removed from either bone or enamel surfaces. A rubber-based molding compound (Silastic a RTV \#3110; Tool Chemical Company, Ferndale, Michigan) was immediately prepared, spread over the scratched surfaces, allowed to dry and removed. This mold was then filled with an epoxy casting solution (Epoxy Resin \#310; Michigan Fiberglass Sales, East Detroit, Michigan). These molds were centrifuged to eliminate air bubbles. Twenty-four hours later, the casts were removed from the molds and mounted on SEM stubs.

A vacuum unit designed to prevent damag. ing heat sensitive material was used to vapor coat the casts with gold. These casts were examined at low power $(\times 50, \times 100)$ for orientation and at high magnification $(\times 600, \times$ $1,000, \times 5,000, \times 10,000)$ to examine individual wear striations. Micrographs were taken of those specimens showing distinct and clearly striated teeth.

The utilization of casts instead of the actual specimens not only facilitates SEM studies to be conducted at a home institution but it also prevents damaging the original specimens. The documentation of fine detail at low and high magnification is comparable (compare fig. 5A to fig. 5B) and no differences can be observed until $\times 6,000$ magnification is reached. At this magnification, the distinctive characteristics of epoxy structure appear but it still may be possible to distinguish aspects of tooth wear from epoxy material characteristics.

\section{RESULTS AND DISCUSSION}

\section{Method I}

Patterns of individual wear striations on the worn teeth of American Indians and Phenacolemur are found to be similar to those experimentally produced by Method I. Figure $4 \mathrm{~A}$ illustrates the surface of a newly erupted incisor before the striations were experimentally produced. Note the lack of any striations, pits or preservation damage on the tooth surface. Figures $4 B, C$ and D illustrate the striations on the control group specimens after the experiment was performed; these show certain characteristics that correspond to the direction the tooth was drawn across the gritty, glass surface. The direction these teeth were drawn across the glass surface is indicated by large arrows. At the point of contact, there is a pit (beveled, round or angular) produced by a particle of sand sandwiched between the enamel and glass surfaces. As the particle of sand is drawn across the tooth surface, an extending broad groove which gradually becomes narrower is produced. Not all individual wear striations produced experimentally by hand clearly show this pattern (fig. $4 \mathrm{E}$ ). However, it is important to note that no wear striations on the control group specimens show a reverse pattern, i.e., striations that begin with a narrow groove which gradually becomes broadly grooved and end with a pit. Therefore, it appears that some individual wear striations can be used to determine the direction of wear.

\section{Method II}

Patterns of individual wear striations pro- 
duced by the unidirectional motor driven mechanical wear machine also are found to be similar to those produced using Method I (see above). However, the wear machine produces striations that are closely aligned and linear. In many instances, striations that begin with a pit and have extending grooves which become narrower can be observed; characteristics that indicate the direction of wear. Although many striations appear to be strictly linear without having a broad pit at the point of contact or a narrowing, extending groove, as in Method I, there are no striations that show a reverse pattern, i.e., striations that begin with narrow grooves which gradually become broad and end with pits.

Variation in pit size and shape and groove width may be related to the size and shape of the particle of grit as well as to the vertical force on the tooth surface when the striation is produced either experimentally or during mastication (see below). For example, the angularity of the pit and groove in figures $5 \mathrm{E}$ and $F$ possibly correspond to the angular shape of the silicon carbide particles. Further, measurements taken from micrographs of individual wear striations produced experimentally using Method II $(n=43)$ clearly indicate the relationship between pit size at the point of contact and particle size (table 1). Although the mean pit size is consistently smaller than

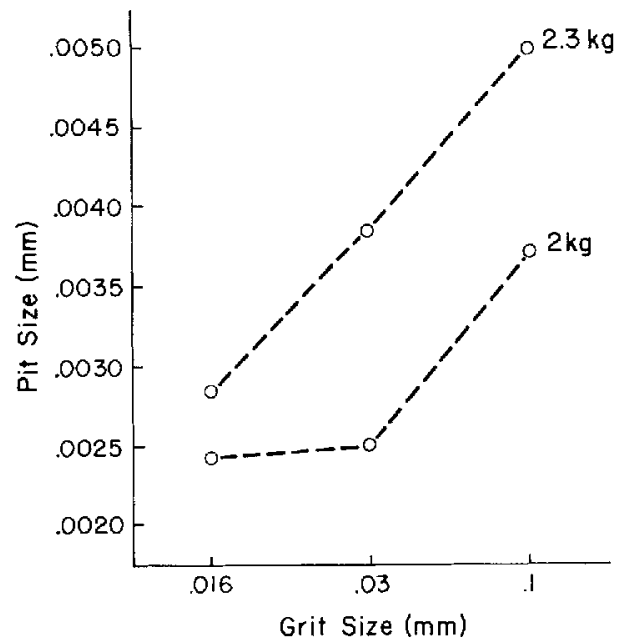

Fig. 2 Scatter plot to illustrate the relationship between mean pit size at the point of initial contact (table 1) and mean grit size. Note that pit size is proportionally larger when the vertical force is increased from $2.0 \mathrm{~kg}$ to $2.3 \mathrm{~kg}$. the mean grit size, these two variables are highly correlated $\left(r_{\mathrm{s}}=+1.0\right.$, see fig. 2$){ }^{1}$ When weights are added to the load arm, increasing the vertical force to $2.3 \mathrm{~kg}$, pit size appears to be proportionally larger and also is highly correlated with grit size (fig. 2). However, using a $2.3 \mathrm{~kg}$ vertical force produces a polished wear facet exhibiting few striations (fig. $5 \mathrm{~F}$ ). This pattern of wear may be related to an increased amount of abrasion (crushing) as the particles of grit slide across the tooth surface. When the wear machine is permitted to operate for more than 15 seconds, using a $2.3 \mathrm{~kg}$ vertical force, a polished wear facet exhibiting few striations also is produced (fig. $5 \mathrm{E})$. This pattern of wear may be related to both an increased amount of abrasion and the result of striations being worn away by repeated linear movements of the slide assembly. These findings may indicate that striations which are produced during mastication occur only under certain conditions involving a combination of occlusal forces, particle size and consistency. Thus, the ability to document variations in pit and groove morphology may provide detailed information concerning the consistency and kind of grit being introduced into a diet. However, additional experimental and comparative studies are needed to determine the relationship between variation in striation pit and groove morphology and dietary factors such as the kind of grit found in plant foods and introduced into a diet by different food processing techniques (e.g., the utilization of manos and metates employed by many American Indian groups to grind maize into flour). In summary, although pit size and groove width may vary, the results presented here indicate that direction of wear is clearly demonstrated by a characteristic wear striation morphology.

\section{Comparisons with naturally occurring wear striations}

Figure 6A illustrates an American Indian upper left maxillary second premolar at low magnification (see figs. 3A,B for orientation). The striations on this tooth begin near the border of lingual cusp and extend toward the base of the crown. At high magnification of the same specimen, the SEM micrographs of individual wear striations exhibit characteristics similar to those observed on the experi-

\footnotetext{
' The Spearman rank correlation coefficient is used only to give an indication of the association between mean pit size and mean grit size; larger samples are needed.
} 


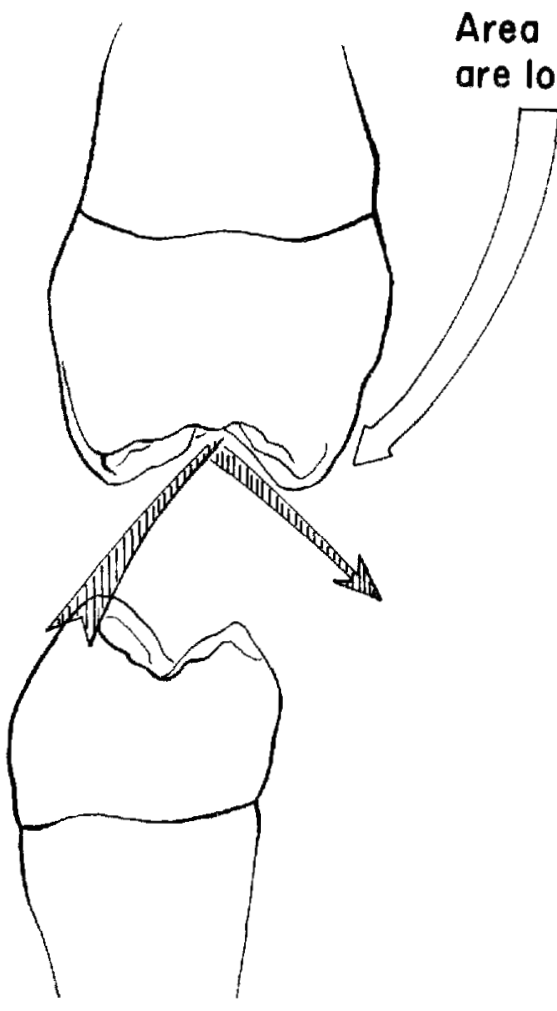

A

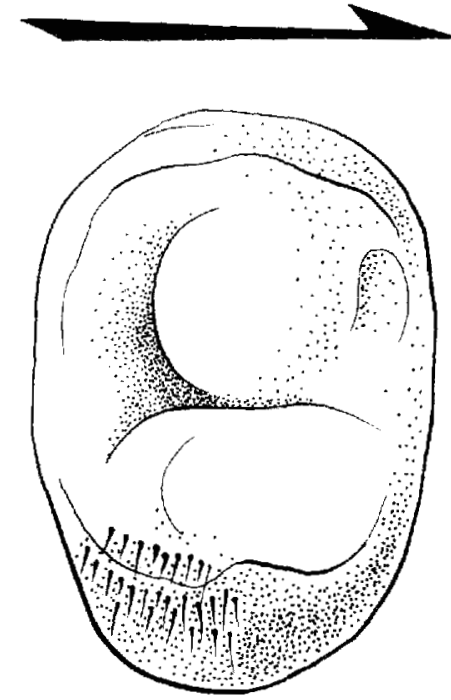

B

Fig. 3 A. Distal aspect of American Indian maxillary and mandibular second left premolars to illustrate schematically movement of the jaw during mastication. In the buccal phase, the lower premolar is moving upward, forward and slightly medially into centric occlusion (left part of arrow) and in the lingual phase, downward, forward and medially out of centric occlusion (right part of arrow). Large white arrow indicates where scanning electron micrographs were taken to illustrate the buecal phase striations possibly produced by tooth-tooth contact during the buccal phase of mastication. B. Occlusal aspect of the maxillary left second premolar to illustrate the location of buccal phase wear striations. Large black arrow is buccal to tooth and points distally. This orientation was used to take the scanning electron micrographs.

mental control specimens (compare figs. $4 \mathrm{~B}-\mathrm{D}$ and figs. 5A-F to figs. $6 \mathrm{~B}-\mathrm{D}$ ). These striations appear to correspond to jaw movements documented by Butler ('52) and Mills ('55) when the mandible is drawn upward, forward and slightly medially during the buccal phase of mastication (fig. 3A). Evidence for abrasion as the result of tooth-food-tooth contact is also illustrated by the pitted surface surrounding individual wear striations. The angularity of the pit and groove illustrated in figure $6 \mathrm{C}$ may indicate that this particular striation was produced by a more angular grit particle resulting in a slice-like appearance.

Individual wear striations on other worn teeth of American Indians and on the cheek teeth of Phenacolemur (fig. 6E) show similar characteristics discussed here and apparently also correspond to certain movements of the jaw.

\section{CONCLUSIONS}

This study provides experimental evidence that it is possible to determine the direction of mandibular movement from a detailed analysis of individual wear striation morphology on the cheek teeth of primates. The data provided by this investigation can be used to confirm, modify or reject competing hypotheses mentioned above concerning the direction of mandibular movement in certain living and extinct mammals. It can be shown that varia- 
tion in wear striation morphology is probably related to the forces of mastication as well as to the kind and consistency of grit particles introduced into a diet. When jaw movements and wear striation morphology are documented in many other animals a more useful interpretation of occlusal relations and certain aspects of diet can be made. A detailed study, similar to the one presented here, of jaw movements in fossil hominoids which may help to clarify certain aspects of the primate masticatory apparatus and dental adaptation during the course of primate evolution is presently in progress.

\section{ACKNOWLEDGMENTS}

This investigation was supported, in part, by the Museum of Anthropology, The University of Michigan. The unidirectional motor driven mechanical wear machine was designed by Doctor Ed Wilmsen to study aspects of wear on stone tools. Ms Jane Mariouw drew figures 2 and 3 . The author thanks Doctors $C$. Loring Brace, Philip D. Gingerich, John Speth, Milford H. Wolpoff and Mr. Wm. K. Macdonald for comments and discussion relating to this paper. I also thank P. J. Hollingsworth, L. F. Allard and A. J. Mardinly for their technical assistance with the SEM. Comments by two anonymous reviewers improved the manuscript.

\section{LITERATURE CITED}

Butler, P. M. 1952 The milk-molars of Perissodactyla, with remarks on molar occlusion. Proc. Zool. Soc. Lond., 121: $777-817$.

Butler, P. M., and J. R. E. Mills 1959 A contribution to the odontology of Oreopithecus. Bull. Brit. Mus. Nat. Hist. (Geology), 4: 3-26.

Crompton, A. W., and K. M. Hiiemae 1970 Functional occlusion and mandibular movements during occlusion in the American opossum, Didelphis marsupialis. Zool. J. Linn. Soc., 49: 21-47.

Dahlberg, A. A., and W. Kinzey 1962 Étude microscopique de l'abrasion et de l'attrition sur la surface des dents. Bull. Group. Int. Rech. Sc. Stomat., 5: 242-251.

Every, R. 1960 The significance of extreme mandibular movements. Lancet, 2: 37-39.

1965 The teeth as weapons; their influence on behavior. Lancet, 1: $685-688$.

1970 Sharpness of teeth in man and other primates. Postilla (Peabody Museum), 143: 1-30.
Gingerich, P. D. 1972 Molar occulsion and jaw mechanics of the Eocene primate Adapis. Am. J. Phys. Anthrop., 36: 359-368.

1973 Molar occlusion and function in the Jurassic mammal Docodon. J. Mammal., 54; 1008-1013. 1976 Cranial anatomy and evolution of early Tertiary Plesiadapidae (Mammalia, Primates). Univ. Michigan Pap. Paleont., 15: 1-140.

Hayat, M. A. 1975 Principles and Techniques of Electron Microscopy Biological Applications. Vol. 5. Van Nostrand Reinhold Co., New York.

Hearle, J. W. S. 1972 Introduction to scanning electron microscopy. In: The Use of the Scanning Electron Microscope. J. W. S. Hearle, J. T. Sparrow and P. M. Cross, eds. Pergamon Press, New York, pp. 1-23

Hiiemae, K. M., and R. F. Kay 1973 Evolutionary trends in the dynamies of primate mastication. In: Symp. Fourth Int. Cong. Primatology, 3. Karger, Basel, pp. 28-64.

Kay, R. F. 1973 Mastication, Molar Tooth Structure, and Diet in Primates, Ph.D. Thesis, Yale University.

1975 The functional adaptations of primate molar teeth. Am. J. Phys. Anthrop., 43: 195-216.

1977 The evolution of molar occlusion in the Cercopithecidae and early Catarrhines. Am. J. Phys. Anthrop., 46: 327.352 .

Kay, R. F., and K. M. Hiiemae 1974a Jaw movement and tooth use in recent fossil primates. Am. J. Phys. Anthrop., 40: $227-256$.

1974b Mastication in Galago crassicaudatus, a cineflourographic and occlusal study. In: Prosimian Biology. R. D. Martin, G. A. Doyle and A. C. Walker, eds. Duckworth, London, pp. 501-530.

Mills, J. R. E. 1955 Ideal dental occlusion in the primates. Dent. Practnr., Bristol, 6: 47-61.

1963 Occlusion and malocclusion of the teeth of primates. In: Dental Anthropology. D. R. Brothwell, ed. Pergamon Press, Oxford, pp. 29-52.

__ 1967 A comparison of lateral jaw movements in some mammals from wear facets on the teeth. Archs. Oral Biol., 12: 645-661.

Molnar, S, 1971 Human tooth wear, tooth function and cultural variability. Am. J. Phys. Anthrop., 34: 175-189. 1972 Tooth wear and culture: A survey of tooth functions among some prehistoric populations. Current Anthropology, 13: 511-525.

Ohnsorge, J., and R. Holm 1973 Scanning Electron Microscopy: An Introduction for Physicians and Biologists. Georg Thieme Publishers, Stuttgart.

Puech, P.-F. 1977 Recherche sur l'alimentation de l'Homo erectus de Tautavel, le crâne et la face humaine les plus anciens d'Europe. L'information Dentaire, 28: 13-18.

Ryan, A.S. 1978 A preliminary scanning electron microscope examination of wear striation direction on primate teeth. J. Dent. Res., in press.

Shkurkin, G. V., A. J. Almquist, A. A. Pfeihofer and E. L. Stoddard 1975 Scanning electron microscopy of dentition: Methodology and ultrastructural morphology of tooth wear. J. Dent. Res., 54: 402-406.

Walker, P. L. 1976 Wear striations on the incisors of cercopithecid monkeys as an index of diet and habitat prefer ence. Am. J. Phys. Anthrop., 45: 299-308. 


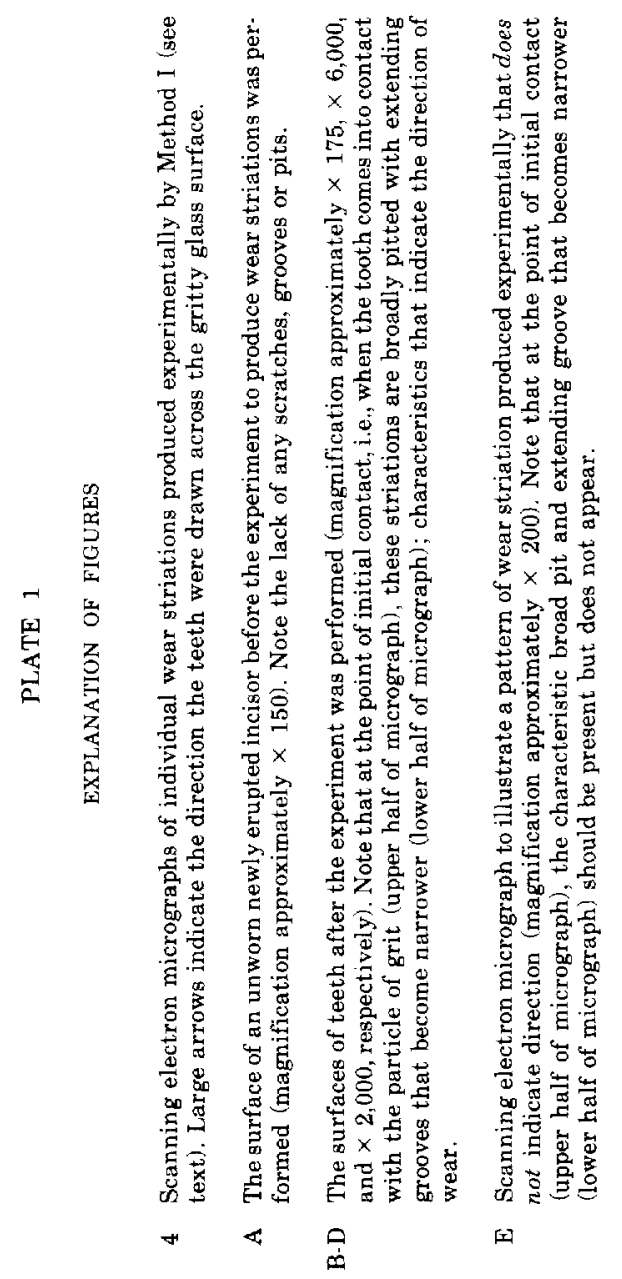



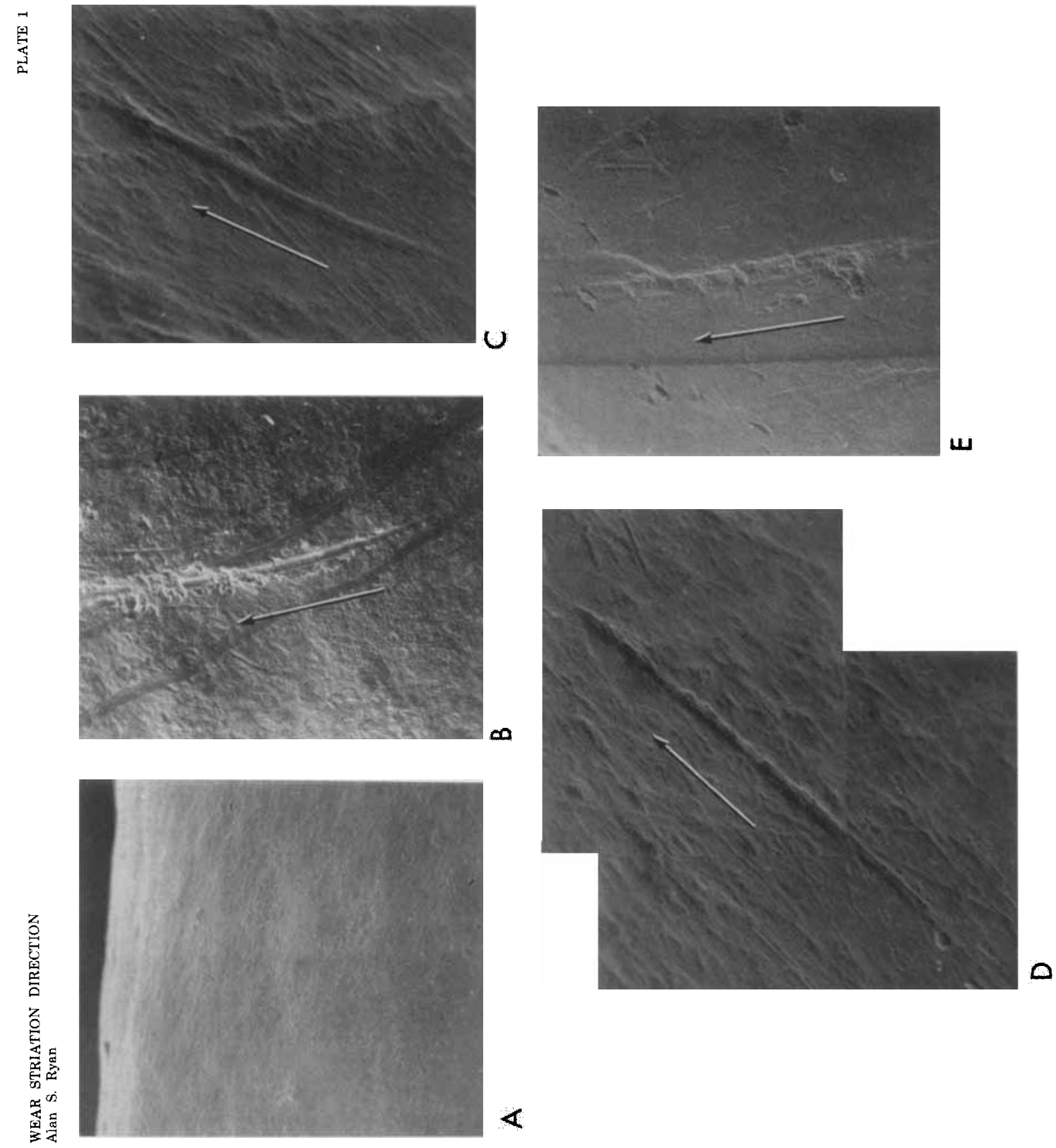

4 


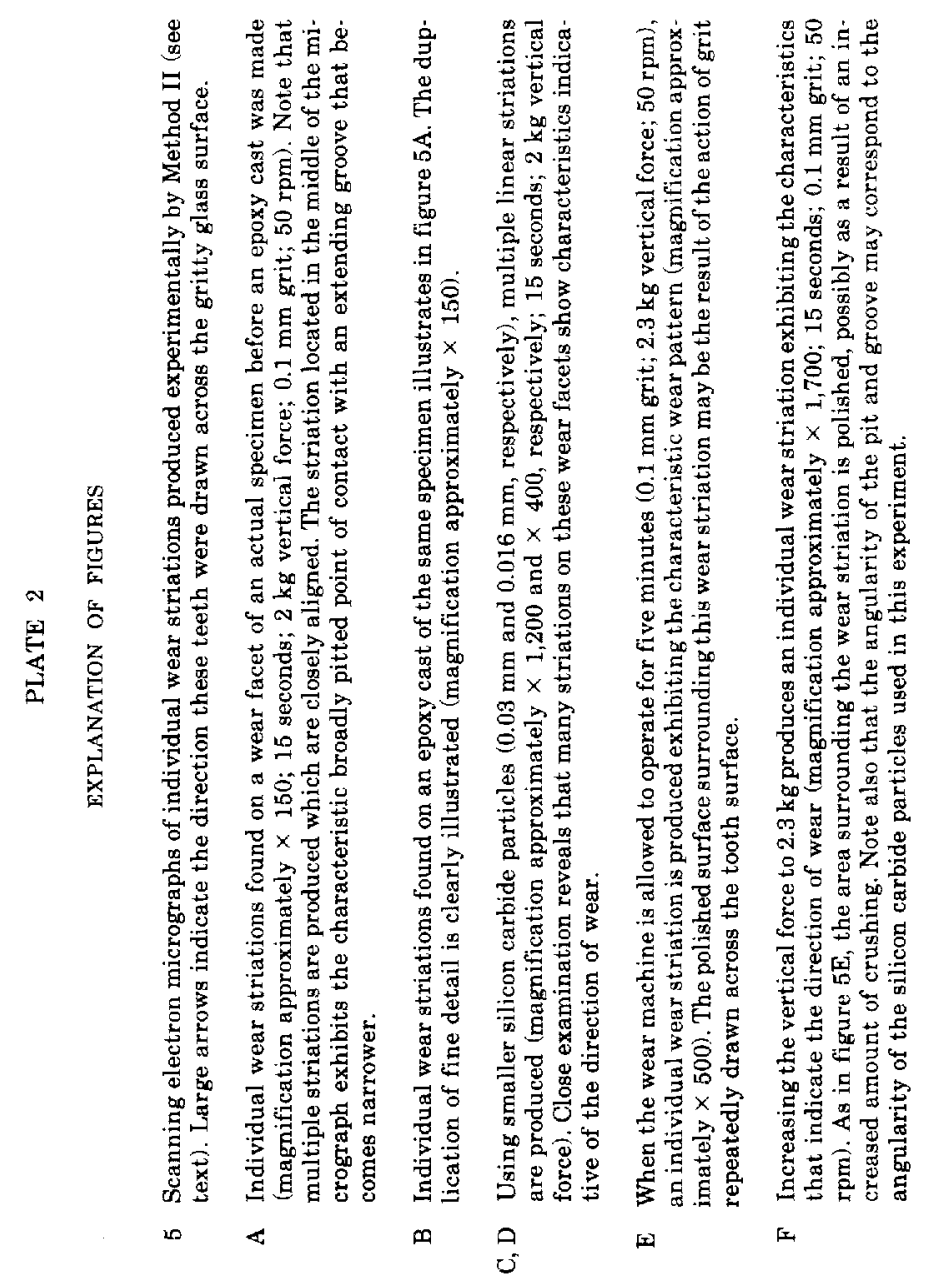


里
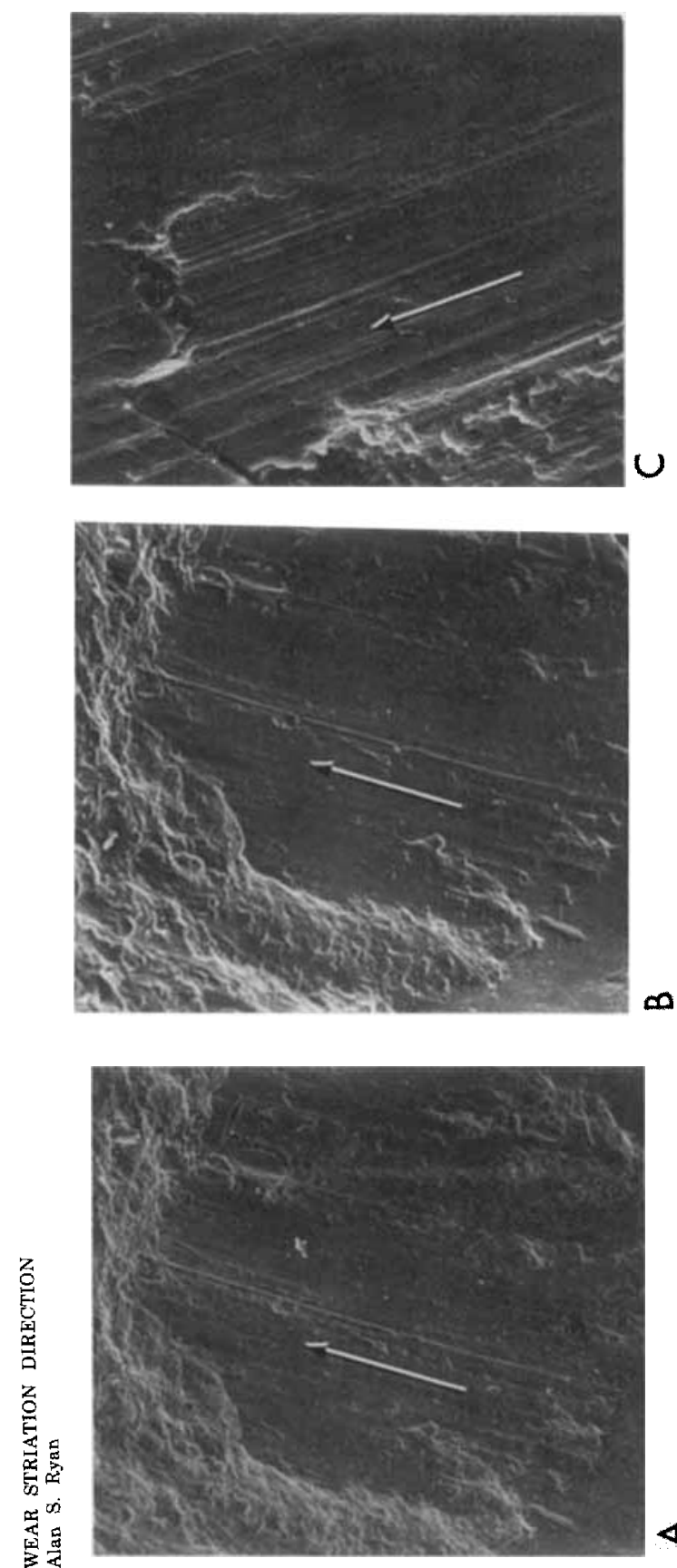

$\infty$
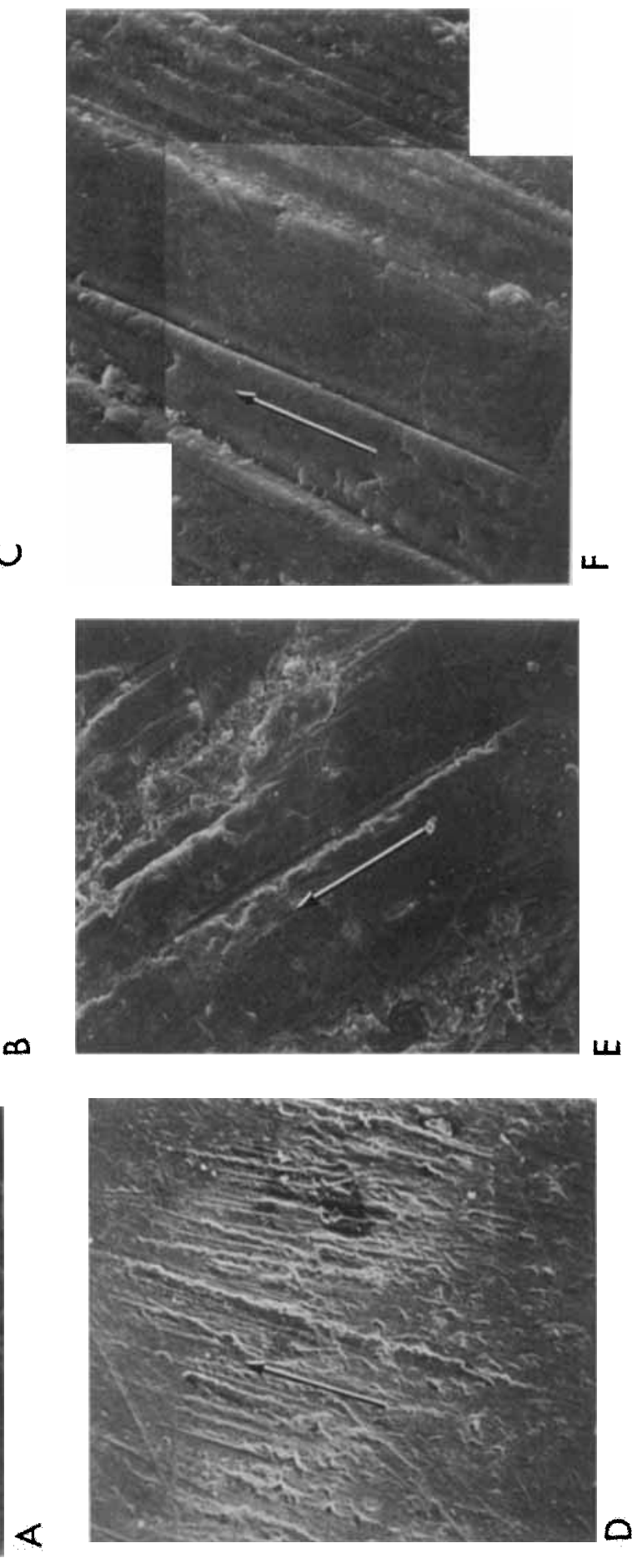


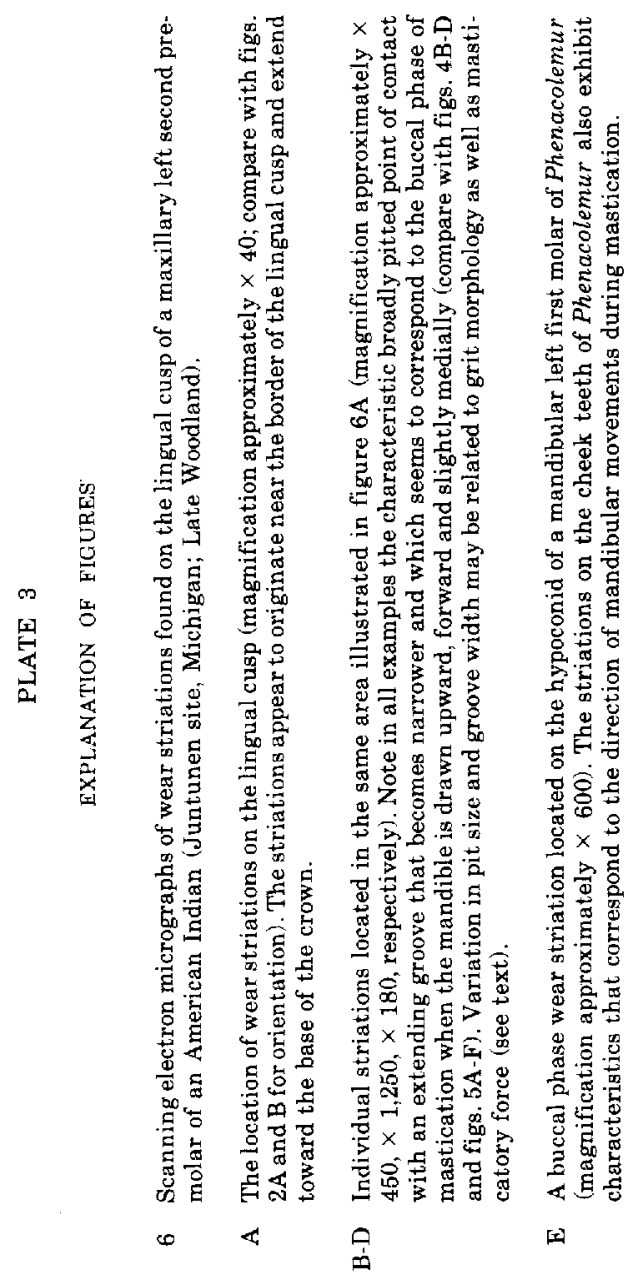



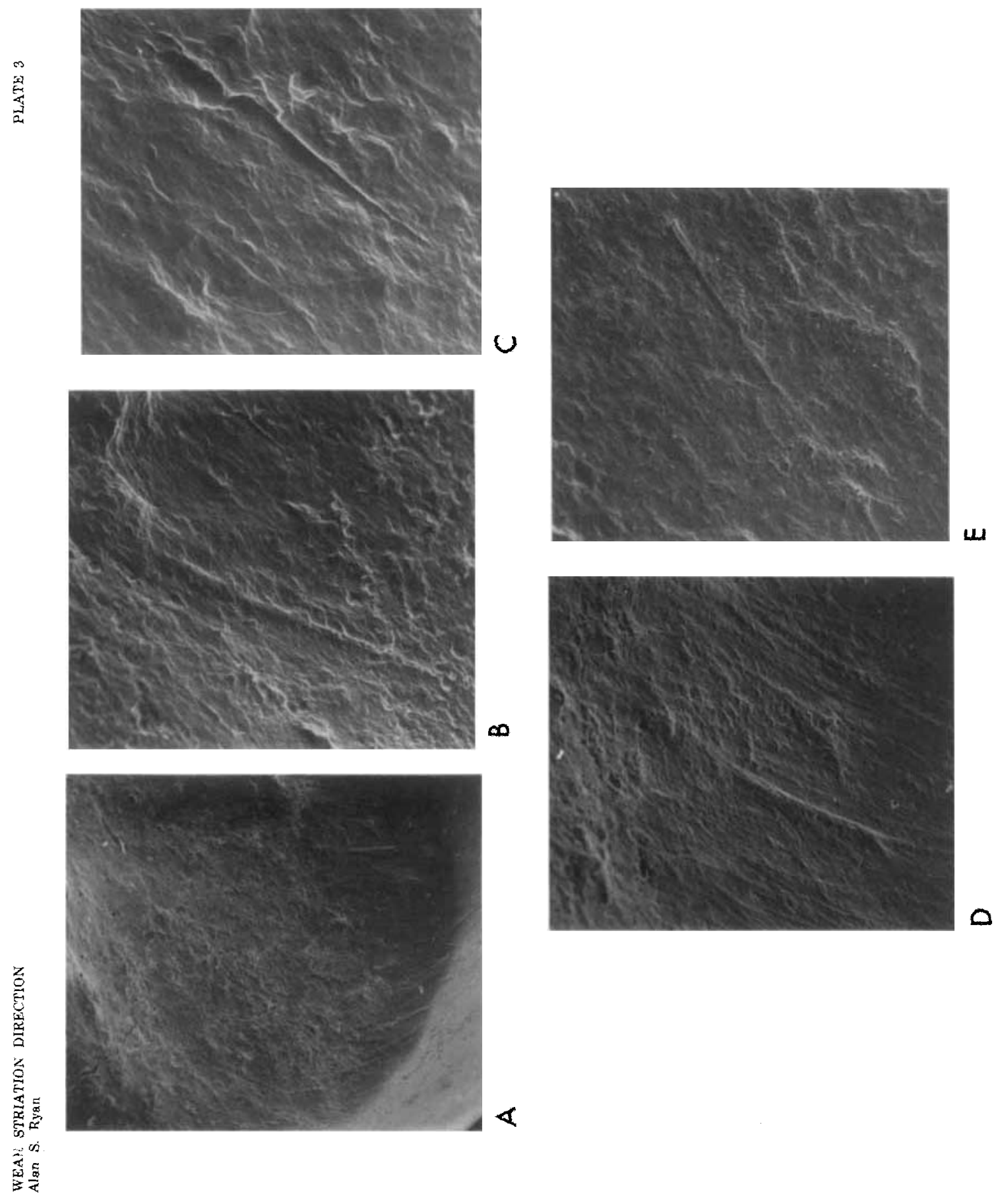